\title{
A mediação cultural na biblioteca escolar
}

\author{
Diego Andres Salcedo \\ Riane Melo de Freitas Alves \\ Universidade Federal de Pernambuco - UFPE, Brasil
}

\section{OPINION}

\begin{abstract}
Resumo
Inúmeras são as bibliotecas escolares e muitos são os jovens estudantes que precisam frequentá-la para o auxílio em suas atividades ou para simplesmente ter um local silencioso para a concentração. Mas a biblioteca escolar pode ter muito mais a oferecer. O bibliotecário pode trabalhar como mediador e levar àquele ambiente, diversas atividades para o aperfeiçoamento do processo de aprendizagem cultural daquele público. A mediação cultural pode ser feita sob diversas formas, levando peças, pinturas, exposições das mais variadas formas a este local, tornando-se assim, um dispositivo cultural. E tão importante para o funcionamento deste dispositivo, é a interação das equipes ligadas à mediação. Um espaço físico adequado e mediadores conectados com o mundo atual são alguns dos fatores para a elaboração de uma boa mediação. A biblioteca escolar é analisada como um meio em que a cultura (seja ela qual for) é encaminhada para esse público tão curioso, que possui a mente aberta para entrada de conhecimentos diversos, e consequentemente, indivíduos culturalmente ricos serão criados.
\end{abstract}

Palavras-chave

Biblioteca ; Cultura ; Escola ; Mediação

\section{Culture mediation in school libraries}

\begin{abstract}
Many are the schools libraries, and many are the young students who need to attend it for assistance in their activities or simply have a quiet place to concentrate. But the school library may have much more to offer. The librarian can work as a mediator and bring to that environment various activities for the improvement of the cultural learning process of that audience. The cultural mediation can be done in various ways like playing, painting, exhibiting as such transforming it in a cultural device. And just as important as for the operation of this device, it is the interaction of the groups linked into mediation. An adequate phisycal space and mediators connected with the current world are some of the factors for the development of a good mediation. The school library is analyzed as a way in which the culture (whatever it is) is forwarded to that such cusiour audience, that has an open mind to the entrance of differente knowledge and hence culturally rich individuals are created.
\end{abstract}

Keywords

Culture ; Library ; Mediation ; School

\section{Introdução}

A Biblioteca Escolar tem um papel relevante naquilo que diz respeito à formação dos estudantes, é nela onde grande parte dos jovens deve passar boa parte do tempo, pois ela é um "centro ativo de aprendizagem" (FRAGOSO, 2002, p. 01). No que compete à Mediação Cultural, a biblioteca escolar torna-se um dispositivo cultural, onde a cultura é o foco principal, e é exposta a partir de uma mediação realizada pelo profissional mediador.

O meio pelo qual as atividades são feitas é o dispositivo. Uma estrutura física bem elaborada nesse aspecto é necessária para uma mediação ideal. Assim como um profissional que conheça todo o processo de atividade e saiba passa-lo adequadamente para o público interessado, que nesse caso é o público da biblioteca escolar. 
Importante também é uma equipe bem direcionada e unida. Bibliotecários, professores e família dos jovens alunos precisam estar sempre juntos no processo de aprendizagem. Professores trabalhando e reforçando as atividades no ambiente da sala de aula, a família aconselhando e direcionando esses jovens aos seus caminhos mais propícios, e os bibliotecários (ou mediadores) atuando na ação principal, pondo em prática o dinamismo da mediação.

A biblioteca escolar como dispositivo cultural será o ponto principal deste trabalho, tendo como objetivos apontar as atividades que devem ser feitas neste ambiente, explanar sobre o ambiente da biblioteca, e conceituar o dispositivo cultural, a partir do ponto de vista da mediação dentre vários aspectos.

\section{Biblioteca escolar}

A biblioteca é um espaço para leitura e aprendizado. Há diversos tipos delas, como a biblioteca especializada, comunitária, pública, universitária, e a biblioteca escolar. Crianças e adolescentes, em sua grande maioria, são o público alvo das bibliotecas escolares.

Atividades de sala de aula são trabalhadas nesta biblioteca, mas não necessariamente este ambiente deve prenderse a isso. Os profissionais que ali trabalham (bibliotecário, ou qualquer outra pessoa), devem incentivar, juntamente com os professores e toda a equipe escolar, a leitura de jovens e crianças, de forma não obrigatória, de uma forma que eles sintam vontade de ir em busca do conhecimento.

Kuhlthau (1998) aborda o tema "Sociedade da Informação", e revela os resultados obtidos sobre os elementos básicos de uma biblioteca escolar da chamada sociedade da informação em um projeto para bibliotecas escolares americanas, chamado "Library Power Project". São eles: 1. financiamento adequado para recursos e tecnologia; 2. bibliotecário em tempo integral, com competência no uso dos recursos e da tecnologia; 3 . planejamento que permita que as classes possam trabalhar em projetos, por longos períodos de tempo; 4. planejamento e ensino cooperativos, envolvendo capacitação profissional intensa para professores, bibliotecários e diretores da escola. (KUHLTHAU, 1998, p.13).

É importante a adaptação e atualização das bibliotecas escolares diante dessas novas tecnologias, pois elas lidam com jovens e crianças curiosos, que buscam facilidade na hora da busca de algum tipo de informação. E para isso, é importante a formação de toda a equipe escolar, não só do bibliotecário. E mais importante ainda, é a união dessa equipe. Para que busquem sempre objetivos em comum.

Professores e bibliotecários precisam caminhar juntos. Aquilo que se é aprendido em sala de aula pode ser aperfeiçoado na biblioteca, e aquilo que se é encontrado na biblioteca pode ser levado e debatido em sala de aula. Mas nem sempre isso acontece. Fragoso (2002) menciona que o bibliotecário é conhecido como "entregador de livros", e que ele próprio muitas vezes se exclui das atividades escolares. E que o professor algumas vezes despreza o bibliotecário, ou não sabe do valor que aquele profissional possui. É necessária uma integração entre sala de aula e biblioteca, que só traria benefícios aos alunos e aos próprios profissionais.

Os primeiros passos de uma pessoa são dados no ambiente escolar, por isso tão importante seria se os professores e bibliotecários, juntamente com a família do estudante, se unissem e incentivassem as primeiras leituras da criança. Se a criança já começa a frequentar uma biblioteca desde cedo, com certeza ela será uma leitora por toda sua vida.

Côrte e Bandeira (2011, p.8) definem a missão das bibliotecas escolares com precisão: "a biblioteca escolar é um espaço de estudo e construção do conhecimento, coopera com a dinâmica da escola, desperta o interesse intelectual, favorece o enriquecimento cultural e incentiva a formação do hábito da leitura".

Além de incentivar a leitura, a biblioteca escolar também pode ser um espaço para a elaboração de várias atividades. Pinturas, contações de histórias, peças infantis com fantoches, etc. Porém, isso nem sempre acontece na realidade das bibliotecas escolares brasileiras. Algumas escolas, em sua grande maioria, públicas, carecem até mesmo de um espaço que possa ser chamado "biblioteca".

A Lei Federal 12.244 de 24 de Maio de 2010, estabelece a implantação de bibliotecas em instituições de ensino públicas e privadas em todo o país. "Os sistemas de ensino do país deverão desenvolver esforços progressivos para que a universalização das bibliotecas escolares [...] efetivada num prazo máximo de dez anos (BRSIL, 2010). Ou seja, com essa Lei é esperada a criação de bibliotecas em todas as escolas do país até 2020. Que mais leituras, 
mais brincadeiras e mais atividades culturais sejam feitas nessas bibliotecas. Assim, essas crianças e jovens se tornarão cidadãos de responsabilidade, e crescerão impulsionados a sempre buscarem conhecimentos diversos, atividades e leituras que mais lhe agradem.

\section{Dispositivos culturais}

A biblioteca é um espaço de aprendizado, é um espaço cultural. Um ambiente de comunicação, um suporte para trocas de conhecimentos. Portanto, a biblioteca pode ser considerada um dispositivo cultural. Eles possuem o papel de transmitir, através de alguma mediação, a informação exigida ou propiciada à determinadas pessoas.

Os dispositivos auxiliam a mediação cultural, que segundo Davallon (2003, p.4)

visa fazer aceder um público a obras (ou saberes) e a sua acção consiste em construir um interface entre esses dois universos estranhos um ao outro (o do público e o, digamos, do objecto cultural) com o fim precisamente de permitir uma apropriação do segundo pelo primeiro.

Os dispositivos culturais, portanto, auxiliam no ato de mediar. Dão apoio ao mediador, sendo o dispositivo físico ou virtual. Museus, arquivos, galerias de arte, feiras, bibliotecas, são alguns dos exemplos de dispositivos culturais. A palavra "dispositivo" está ligada à ação de dispor, ou seja, colocar em certa ordem. E é esse o papel desses ambientes culturais, ajustar e unir os componentes do ciclo da mediação: mediador - objeto - mediado.

Os dispositivos também estão bastante ligados à sociedade em que se encontram. Aliás, não existe dispositivo sem sociedade, pois a sociedade legitima o dispositivo. Cada grupo possui a sua cultura, e estabelece, assim, a sua maneira de viver em um ambiente. E os dispositivos culturais modificam-se e desenvolvem-se a partir das necessidades desses grupos e dessa nova "sociedade da informação".

Há a necessidade de mudanças em todos os aspectos vivenciados pelos seres humanos. A arte transfigura-se a todo o momento, as pessoas evoluem em determinados pensamentos, com isso, os dispositivos culturais também se modificam, consequentemente.

Foucault trata os dispositivos de uma maneira mais ampla, afirma que "um dispositivo se caracteriza por um conjunto heterogêneo de elementos" (2006, p. 244). E assegura que eles geram sentidos na sociedade, a partir das relações que estabelecem. (DELEUZE, 1997 apud KLEIN 2007). Ou seja, é um ciclo vicioso, "é uma maquinaria que funciona e faz funcionar" (SANDER, 2011, p.133).

Peraya (1999 apud KLEIN, 2007) aponta uma ligação entre sociedade, tecnologia e linguagem para a definição dos dispositivos. A união desses fatores é o que faz sentido a essa mídia/ambiente denominada dispositivo. Pois ele próprio é o que provoca a interação entre esses universos, fazendo o seu papel de conectar e dar sentido ao ato de comunicação entre esses fatores determinantes.

A cultura é um modo de viver de um povo. São hábitos, línguas, danças, comidas, e muitos outros fatores que diferem cada região, cada grupo de pessoas. Coelho (2008, p. 42) cita Raymond Williams, e diz que cultura é "um sistema de significação pelo qual uma ordem social é vivida, explorada, comunicada e reproduzida".

E é exatamente isso: reproduzida. A cultura de cada local e de cada povo, precisa ser mostrada para seu aperfeiçoamento e para o conhecimento daqueles que se interessam em buscar sempre algo novo. E essa cultura deve ser exposta sob diversas formas na Mediação Cultural, como pinturas, exposições, danças, peças teatrais, leituras. Tudo isso através daquilo que apoia todo o processo, o dispositivo cultural.

\section{Biblioteca escolar como dispositivo de ação}

Uma biblioteca é popularmente conhecida como um ambiente para ler-se em silêncio, um local para empréstimos e devoluções de livros. Um pensamento retrógrado que ainda perdura no imaginário coletivo. A biblioteca (seja ela qual for) é um espaço rico em conhecimento, e precisa ser libertada de qualquer tipo de preconceito. 
A biblioteca escolar tem um papel fundamental em uma escola, seja ela pública ou privada. Pouco é o reconhecimento dado a este espaço, mas Fragoso (2002, p. 127) já afirma que "embora tão marginalizada de nosso sistema educacional, a biblioteca escolar tem funções fundamentais a desempenhar e que podem ser agrupadas em duas categorias - a educativa e a cultural." Por isso acreditamos nem só de atividades de sala de aula deve sobreviver uma biblioteca escolar. Com essa abordagem cultural, ela se torna um complemento da educação formal. O seu público cresce com ideias e argumentos formados, e nisso, nasce uma mente crítica nesses jovens leitores.

A biblioteca pode ser considerada um patrimônio cultural, que de acordo com a Constituição de 1988 tem como definição: "os bens de natureza material e imaterial, tombados individualmente ou em conjunto, portadores de referência à identidade, à ação, à memória dos diferentes grupos formadores da sociedade brasileira." Além de muitas bibliotecas serem históricas, e nascerem em momentos marcantes da história do país, elas possuem o conhecimento resguardado. De História do Brasil à História mundial, línguas, religião, mapas, culinária, e tantos outros assuntos são, ou deveriam ser, abordados pelas bibliotecas.

A biblioteca escolar não foge disso. Livros didáticos devem conter neste espaço, mas também materiais de assuntos diversos. É necessário que desde cedo esse público entenda que "o mundo" está presente na biblioteca, para que a curiosidade seja despertada e ele tome conhecimento das mais variadas culturas existentes.

É necessária a preservação das bibliotecas para a continuidade das manifestações culturais. E sua comunidade, assim como os profissionais, são igualmente responsáveis pelos cuidados e zelo para com este ambiente.

As escolas estão em cada parte dos municípios brasileiros, então, conclui-se dizer que as bibliotecas escolares são maioria dentre todas as outras (levando-se em consideração a Lei 12.244). Por isso é tão importante a democratização da cultura neste ambiente, para, cada vez mais, o acesso aos bens culturais sejam ampliados.

Almeida (2008, p. 03) cita as "Teorias da Ação" como um das ligações da Mediação. E define as mediações como "as conexões que se estabelecem entre as ações sociais e as motivações (individuais e/ou coletivas)." Mas para ocorrer uma conexão bem elaborada, é necessário um profissional preparado para gerir os espaços e suas ações.

Um bibliotecário, professor, ou até mesmo outro profissional, será, na prática, um mediador cultural. Como mediador, ele precisa estar bem preparado, ser dinâmico, e saber lidar com situações diversas que ocorrerão durante o processo de mediação.

Davallon (2003 apud Almeida 2008 p. 03) argumenta que a mediação:

Envolve coisas muito diferentes entre si, que abarcam desde as velhas concepções de "atendimento ao usuário", passando pela atividade de um agente cultural em uma dada instituição[...] até a construção de produtos destinados a introduzir o público num determinado universo de informações e vivências (arte, educação, ecologia, por exemplo), chegando à elaboração de políticas de capacitação ou de acesso às tecnologias de informação e comunicação etc.

O bibliotecário de uma biblioteca escolar precisa estar a par de todos esses fatores. Indicar leituras tanto para as atividades escolares, tanto para o lazer; incitar esses jovens a ir em busca da arte em geral, através de livros, pinturas, produções audiovisuais, peças teatrais, etc. E também estar ciente do avanço rápido da tecnologia, atualizando-se cada vez que algo novo surgir, e estar ao lado dos usuários também nesses meios.

O espaço físico de uma biblioteca também é um fator importante, pois de nada adianta tantas atividades em mente, sem um suporte físico que as coloque em prática. Outro fator é a climatização. As leituras e mediações diversas precisam ser feitas em um ambiente confortável.

Os gestores e profissionais da informação devem atuar como mediadores culturais, e preparar um espaço em que todos se sintam bem e acolhidos, e planejar atividades culturais que levem discussões, criações, e interpretações ao público leitor, apresentando a biblioteca escolar como um dispositivo cultural. 


\section{Considerações finais}

O processo de mediação cultural precisa ser feito por profissionais bem capacitados, em lugares bem estruturados, e com um resultado que atinja o público alvo, de modo que discussões sejam feitas, através de debates e questionamentos.

A biblioteca escolar é um dos tantos dispositivos culturais existentes, porém tem sua importância bastante implícita: lida com jovens aprendizes. Por isso a grande responsabilidade dos profissionais bibliotecários e/ou mediadores culturais que dirigem o processo mediático neste ambiente.

A mediação cultural é um processo importante em vários aspectos, como cinema, teatro, fotografia, dança, etc. E nada melhor que uma biblioteca para abordar todos esses temas de uma forma cultural. Desde cedo esses cidadãos serão despertados a criar formas de ver o mundo ao se questionarem situações que poderiam ter tido outras concepções.

Portanto, a Lei 12.244 deve ser colocada em prática fielmente. Mas além de criações de bibliotecas em todas as escolas brasileiras, é necessária uma conscientização da equipe escolar, e incentivos do governo, para que a cultura propriamente dita prevaleça neste local.

\section{Referências}

ALMEIDA, Marco Antônio de. Mediações da cultura e da informação: perspectivas sociais, políticas e epistemológicas. Tendências da Pesquisa Brasileira em Ciência da Informação, João Pessoa, v.1, n.1, 2008. Disponível em: >http://inseer. ibict.br/ancib/index.php/tpbci/article/viewArticle/6>. Acesso em: 20 maio 2013.

BRASIL. Lei n.ํ 12.244: dispõe sobre a universalização das bibliotecas nas instituições de ensino do País. Brasília: Congresso Nacional, 2010.

COELHO, Teixeira. A cultura e seu contrário: cultura, arte e política pós-2001. São Paulo: Iluminuras: Itaú Cultural, 2008.

CORTE, Adelaide Ramos e; BANDEIRA, Suelena Pinto. Biblioteca Escolar. Brasília: Briquet de Lemos, 2011.

DAVALLON, Jean. A mediação: a comunicação em processo? Revista Prisma.com, Porto, n.4, 2007. Disponível em: <http://revistas.ua.pt/index.php/prismacom/article/viewFile/645/pdf>. Acesso em: 17 maio 2013.

FOUCAULT, Michel. Microfísica do Poder. 22. ed. Rio de Janeiro: Graal, 2006.

FRAGOSO, Graça Maria. Biblioteca na escola. Revista ACB: Biblioteconomia em Santa Catarina. v.7, n. 1, p. 124-131, 2002. Disponível em: <http:/www.brapci.ufpr.br/documento.php?dd0=0000001627\&dd1=18f80>. Acesso em: 17 maio 2013.

KLEIN, Otávio José. A gênese do conceito de dispositivo e sua utilização nos estudos midiáticos. Estudos em Comunicação, Passo Fundo, n.1, p. 215-231, abr. 2007. Disponível em: <http://www.ec.ubi.pt/ec/01/ docs/artigos/klein-otavio-genese-do-conceitode-dispositivo.pdf>. Acesso em: 20 maio 2013.

KUHLTHAU, Carol Collier. O papel da biblioteca escolar no processo de aprendizagem. In: VIANNA, MárciaMilton; CAMPELLO, Bernadete; MOURA, Victor Hugo Vieira. Biblioteca escolar: espaço de ação pedagógica. Belo Horizonte: EB/UFMG, 1999. p. 914. Seminário promovido pela Escola de Biblioteconomia da Universidade Federal de Minas Gerais e Associação dos Bibliotecários de Minas Gerais, 1998, Belo Horizonte.

SANDER, Jardel. Corpo-dispositivo: cultura, subjetividade e criação artística. ArtCultura, Uberlândia, v.13, n. 233, p. 129-142, jul.dez. 2011. 


\section{Dados dos autores}

\section{Diego Andres Salcedo}

Graduado em Biblioteconomia, Mestre e Doutor em Comunicação. Professor no Departamento de Ciência da Informação na Universidade Federal de Pernambuco - Brasil.

salcedo.da@gmail.com

Riane Melo de Freitas Alves

Graduada em Biblioteconomia. Especialista em Mediação Cultural pelo Departamento de Ciência da Informação da Universidade Federal de Pernambuco - Brasil.

riamelo9@gmail.com

$\begin{array}{ll}\text { Recebido-Received } & : 2013-10-12 \\ \text { Aceitado-Accepted } & : 2013-12-30\end{array}$

\section{(oc) EY}

This work is licensed under a Creative Commons Attribution 4.0

United States License.

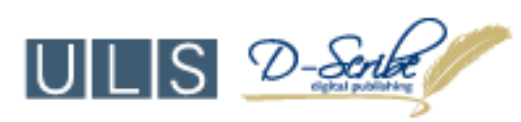

This journal is published by the University Library System of the University of Pittsburgh as part of its D-Scribe Digital Publishing Program and is cosponsored by the University of Pittsburgh Press. 